\title{
Abatement of Nitrogen Oxides in a Catalytic Reactor Enhanced by Nonthermal Plasma Discharge
}

\author{
Young Sun Mok, V. Ravi, Ho-Chul Kang, and B. S. Rajanikanth, Senior Member, IEEE
}

\begin{abstract}
Removal of nitrogen oxides using a nonthermal plasma process (dielectric barrier discharge) combined with catalyst was investigated. In this system, selective catalytic reduction of nitrogen oxides is affected by the operating condition of the plasma process and, thus, the characteristics of the plasma process were separately examined before combining the two processes. The oxidation of $\mathrm{NO}$ to $\mathrm{NO}_{2}$ in the plasma reactor easily took place at room temperature. As the temperature increased, however, the rate of the oxidation greatly decreased, which implies that an additive to increase the reaction rate is necessary. In the presence of ethylene as an additive, the oxidation of NO to $\mathrm{NO}_{2}$ largely enhanced at a temperature range of $100{ }^{\circ} \mathrm{C}-200{ }^{\circ} \mathrm{C}$. Comparison of ac with pulse voltage in terms of the energy efficiency for NO oxidation was made, and almost no difference between the two voltage types was observed. The removal of $\mathrm{NO}_{x}$ on the catalyst $\left(\mathrm{V}_{2} \mathrm{O}_{5} / \mathrm{TiO}_{2}\right)$ was found to largely increase by the plasma discharge. The byproduct formaldehyde formed from ethylene in the plasma reactor could be completely removed in the catalytic reactor while significant amount of carbon monoxide and ammonia slip were observed. The plasma-catalyst system used in this study was able to remove more than $80 \%$ of $\mathrm{NO}_{x}$ (energy yield: $42 \mathrm{eV} / \mathrm{NO}_{x}$-molecule) at a temperature range of $100{ }^{\circ} \mathrm{C}-200{ }^{\circ} \mathrm{C}$ that is much lower than typical temperature window of selective catalytic reduction $\left(250{ }^{\circ} \mathrm{C}-450{ }^{\circ} \mathrm{C}\right)$.
\end{abstract}

Index Terms-Catalytic reduction, $\mathrm{NO}_{x}$, nonthermal plasma, removal, temperature window.

\section{INTRODUCTION}

$\mathbf{T}$ HE REMOVAL of nitrogen oxides $\left(\mathrm{NO}_{x}\right)$ emitted from many industrial processes has become one of the greatest challenges in environmental protection, and various $\mathrm{NO}_{x}$ control technologies such as selective catalytic reduction (SCR), wet scrubbing, electron-beam irradiation, and nonthermal plasma process have been developed so far [1]-[4]. Among these technologies, SCR has been most widely studied due to its many advantages over other technologies [5]. One problem related to the application of SCR to manifold pollution sources may be its temperature window. It is well known that typical SCR catalyst works well around $250^{\circ} \mathrm{C}-450^{\circ} \mathrm{C}$, whereas there are many important pollution sources that the temperatures of the exhaust gases are lower than this window. For instance, the temperature of diesel exhaust is typically $100{ }^{\circ} \mathrm{C}-200{ }^{\circ} \mathrm{C}$

Manuscript received August 5, 2002; revised October 18, 2002. This work was supported by the Korea Ministry of Environment under "The Eco-Technopia 21 Program."

Y. S. Mok and H.-C. Kang are with the Department of Chemical Engineering, Cheju National University Ara, Cheju 690-756, South Korea (e-mail smokie@cheju.cheju.ac.kr).

V. Ravi and B. S. Rajanikanth are with the Department of High Voltage Engineering, Indian Institute of Science, Bangalore 560 012, India.

Digital Object Identifier 10.1109/TPS.2003.808876 though it depends on country and driving conditions, and typical temperature of iron-ore sintering plant is around $150{ }^{\circ} \mathrm{C}$. Therefore, unless traditional SCR technology is modified in order that it may work well at lower temperature, it requires the heating-up of exhaust gas to a certain temperature, which leads to the increase in operation cost.

Generally, among $\mathrm{NO}_{x}\left(\mathrm{NO}+\mathrm{NO}_{2}\right)$ emission, $\mathrm{NO}$ generally has a majority (95\%) and the content of $\mathrm{NO}_{2}$ is less than $5 \%$. According to the literature in connection with SCR [6], it is reported that the performance of SCR is elevated by the increase in the ratio of $\mathrm{NO}_{2}$ to $\mathrm{NO}$. This result indicates that catalytic removal of $\mathrm{NO}_{x}$ at relatively low temperature is possible when a part of $\mathrm{NO}$ is converted to $\mathrm{NO}_{2}$. One easy method to increase the portion of $\mathrm{NO}_{2}$ in $\mathrm{NO}_{x}$ may be nonthermal plasma technology as its capability to oxidize $\mathrm{NO}$ to $\mathrm{NO}_{2}$ has been proved elsewhere [7]-[9]. Bröer and Hammer [10], Hoard [11], and Yoon et al. [12] showed the possibility that the $\mathrm{NO}_{x}$ removal is enhanced and the temperature window is lowered by combining nonthermal plasma with SCR technology.

Typical nonthermal plasma technologies studied so far have usually adopted such procedure as the oxidation of $\mathrm{NO}$ to $\mathrm{NO}_{2}$ or $\mathrm{HNO}_{3}$, followed by formation of fine ammonium nitrate particles which should be collected by a conventional electrostatic precipitator or a bag filter [13]-[15]. Since the formation of ammonium nitrate is a slow reaction and does not take place efficiently at higher temperatures [16], [17], most of such studies have been conducted at temperatures lower than $100{ }^{\circ} \mathrm{C}$, and only few studies performed at high temperatures are available in the literature [18]. However, in order to combine nonthermal plasma with SCR, it is necessary to investigate the plasma discharge characteristics and the behavior of NO oxidation at high temperatures because the plasma discharge is a phenomenon related to gas ionization and the reaction mechanism of NO oxidation depends on gas temperature [19]. In this context, the study on the temperature effect on the nonthermal plasma process should be preceded before combining it with catalyst.

This study deals with the combination process of nonthermal plasma and SCR for the removal of $\mathrm{NO}_{x}$. The plasma reactor used was a coaxial dielectric barrier discharge (DBD) reactor, and the SCR catalyst used was commercial honeycomb $\mathrm{V}_{2} \mathrm{O}_{5} / \mathrm{TiO}_{2}$. As previously mentioned, since the experiments at high temperatures are necessary in order to combine two processes, the study using the plasma reactor alone was conducted first and then the effect of the combined system on $\mathrm{NO}_{x}$ removal was examined. The DBD reactor used can be operated by either ac or pulse voltage [20], [21], and the two voltage types were compared in terms of the energy efficiency for NO conversion. 


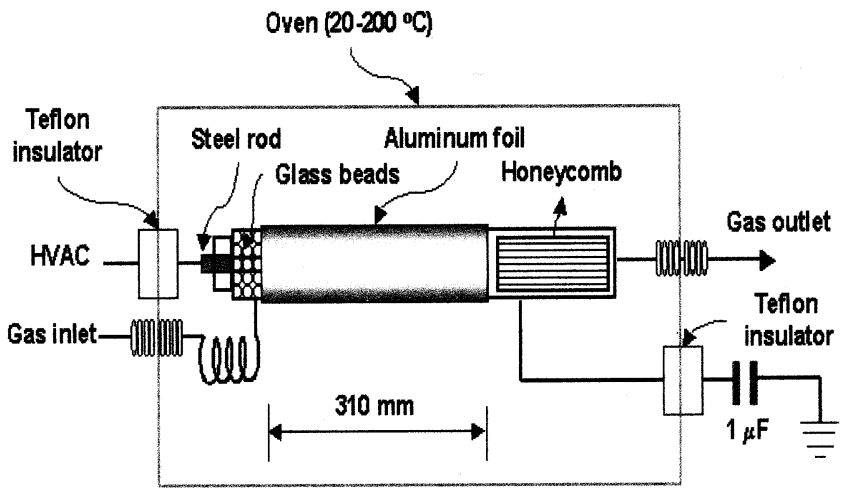

Fig. 1. Schematic of the plasma-catalytic reactor.

\section{EXPERIMENTAL}

\section{A. Description of the Experimental Setup}

The schematic of the reactor system composed of nonthermal plasma reactor and catalytic reactor is presented in Fig. 1. A coaxial dielectric barrier discharge reactor made of a glass tube (inner diameter: $25.8 \mathrm{~mm}$; outer diameter: $30.2 \mathrm{~mm}$ ) and a $3 / 8$ in stainless steel rod was used as the plasma reactor. The stainless steel rod acting as the discharging electrode was positioned in the center of the glass tube. This high-voltage electrode does not go through the catalyst. The space between the glass tube and the discharging electrode was filled with glass beads of $5 \mathrm{~mm}$ in diameter. The outer surface of the glass tube was wrapped with aluminum foil and grounded. The effective length of the plasma reactor where discharge occurs is $31 \mathrm{~cm}$. A $1.0-\mu \mathrm{F}$ capacitor was connected to the plasma reactor in series to measure the discharge power when ac voltage is used, which will be fully explained. In the present study, most of experiments were carried out by making use of ac voltage of $60 \mathrm{~Hz}$, but a comparative study between ac and pulse energization was also made.

The SCR catalyst used was a commercial $\mathrm{V}_{2} \mathrm{O}_{5} / \mathrm{TiO}_{2}$ in the form of honeycomb (20 cells per square inch). The content of vanadium in the catalyst was $5.0 \mathrm{wt} . \%$, and the apparent volume of the honeycomb was $31 \mathrm{~cm}^{3}\left(1.8 \times 1.8 \times 9.7 \mathrm{~cm}^{3}\right)$, which was used for the calculation of space velocity defined as the ratio of feed gas flow rate to reactor volume.

The plasma-catalyst reactor was kept in an oven to maintain the desired gas temperature, and the stainless steel tube connected to the reactor inlet was wound several times within the oven in order to ensure proper heating-up of the feed gas to a given temperature. The main components of the feed gas were nitrogen and oxygen whose flow rates were adjusted by mass flow controllers (MFC) (Model 1179A, MKS Instruments, Inc.). The flow rates of NO $\left(5.0 \%(\mathrm{v} / \mathrm{v})\right.$ balanced with $\left.\mathrm{N}_{2}\right)$, ammonia $(5.0 \%(\mathrm{v} / \mathrm{v})$ balanced with $\mathrm{N} 2)$ and ethylene (pure) were also controlled by mass flow controllers, and they were mixed with $\mathrm{N}_{2}$ and $\mathrm{O}_{2}$.

The experimental conditions are summarized in detail in Table I. The flow rate of the feed gas stream was $5 \mathrm{l} / \mathrm{min}$ (at room temperature), and the concentration of $\mathrm{NO}_{x}\left(\mathrm{NO}+\mathrm{NO}_{2}\right)$ at the reactor inlet was 300 parts per million (ppm, volumetric). The concentrations of ammonia and ethylene were 300 and $750 \mathrm{ppm}$, respectively. Since the typical amount of hydrocarbon in diesel exhaust is around $750 \mathrm{ppm}$, the addition of ethylene may simulate well the real exhaust gas. A modern diesel engine may emit less hydrocarbons (measured as ppm C1) than nitrogen oxides. The experiments were carried out at different reaction temperatures in the range of $100{ }^{\circ} \mathrm{C}-200{ }^{\circ} \mathrm{C}$ by a division of $50{ }^{\circ} \mathrm{C}$, but some experiments were also conducted at room temperature to understand the phenomena related to this system.

The volume of the plasma reactor (inner diameter: $25.8 \mathrm{~mm}$; length: $31 \mathrm{~cm}$ ) is $162 \mathrm{~cm}^{3}$, and, accordingly, the residence time (reactor volume/feed gas flow rate) is calculated to be $1.9 \mathrm{~s}$ at a flow rate of $5 \mathrm{l} / \mathrm{min}$. However, actual residence time should be calculated by considering the void fraction of the reactor and the volume of the electrode $\left(22 \mathrm{~cm}^{3}\right)$. In case of this plasma reactor packed with glass beads, the void fraction was found to be 0.37 . Therefore, the real reactor volume where the reactions take place corresponds to $52 \mathrm{~cm}^{3}$. Recalculation of the actual residence time using the real reactor volume gives $0.6 \mathrm{~s}$. There is one more thing that should be made clear in the calculation of residence time. The residence time $(0.6 \mathrm{~s})$ is based on the flow rate at room temperature, however, it should be corrected when the gas is not at room temperature, because the gas flow rate is a function of temperature.

In case of ac, the variation in the applied voltage can change the discharge power, and it was varied from 4 to $14 \mathrm{kV}$. When pulse voltage was employed to compare it with ac voltage, the spark gap switch depicted in Fig. 2 was used. In this circuit, the pulse-forming capacitor $(396 \mathrm{pF})$ is charged through $20-\mathrm{k} \Omega$ resistor by a negative dc high-voltage power supply (Korea Switching Company). As the voltage on the capacitor reaches the spark-over voltage of the spark gap electrode, the capacitor is discharged, producing narrow positive high-voltage pulses. The pulse frequency is changed by adjusting the charging time of the pulse-forming capacitor, by which way it was varied from 5 to $30 \mathrm{~Hz}$ (pulses/s).

The voltage applied to the discharging electrode was measured by a 1000:1 high voltage probe (PVM-4, North Star Research, Corporation) and a digital oscilloscope (TDS 3032, Tektronix). For the measurement of the voltage between both ends of the 1.0- $\mu \mathrm{F}$ capacitor, a 10:1 voltage probe (Tektronix P6139A) was used. The current in case of using pulse voltage was measured by a current transformer (Pearson Electronics) having the ratio 0.25 V/A. The measurement of input power was carried out using a digital power meter (Model WT 200, Yokogawa).

The concentrations of $\mathrm{NO}$ and $\mathrm{NO}_{2}$ were analyzed by a chemiluminescence $\mathrm{NO}-\mathrm{NO}_{2}-\mathrm{NO}_{x}$ analyzer (Model 42C, Thermo Environmental Instruments, Inc.). This kind of NO- $\mathrm{NO}_{2}-\mathrm{NO}_{x}$ analyzer has a problem in measuring $\mathrm{NO}_{2}$ concentration when ammonia is present, and thus, in some cases, a portable flue gas analyzer (Eurotron) was utilized to analyze $\mathrm{NO}_{2}$ concentration. This portable flue gas analyzer was also used for the measurement of carbon monoxide (CO). Ethylene concentration was detected using a gas chromatograph equipped with a flame ionization detector and a thermal conductivity detector (GC-14B, Shimadzu) and a capillary column (CBP10-M25-025, Shimadzu). Ammonia and formaldehyde concentrations were measured by chemical detectors (Gastec Company, Japan). 
TABLE I

EXPERIMENTAL CONDITION

\begin{tabular}{ll}
\hline Gas flow rate & $5 \mathrm{l} / \mathrm{min}$ \\
\hline Space velocity over catalyst & $12,000 \mathrm{~h}^{-1}\left(100{ }^{\circ} \mathrm{C}\right), 13,600 \mathrm{~h}^{-1}\left(150{ }^{\circ} \mathrm{C}\right)$, \\
& $15,300 \mathrm{~h}^{-1}\left(200^{\circ} \mathrm{C}\right)$ \\
Reaction temperature & 100,150 and $200{ }^{\circ} \mathrm{C}$ \\
Oxygen content in feed gas & $10 \%(\mathrm{v} / \mathrm{v})$ \\
Nitrogen content in feed gas & $90 \%(\mathrm{v} / \mathrm{v})$ \\
Ethylene concentration & $750 \mathrm{ppm}(\mathrm{v} / \mathrm{v})$ \\
NH $H_{3}$ concentration & $300 \mathrm{ppm}(\mathrm{v} / \mathrm{v})$ \\
NOx concentration & $300 \mathrm{ppm}(\mathrm{v} / \mathrm{v})$ \\
\hline
\end{tabular}

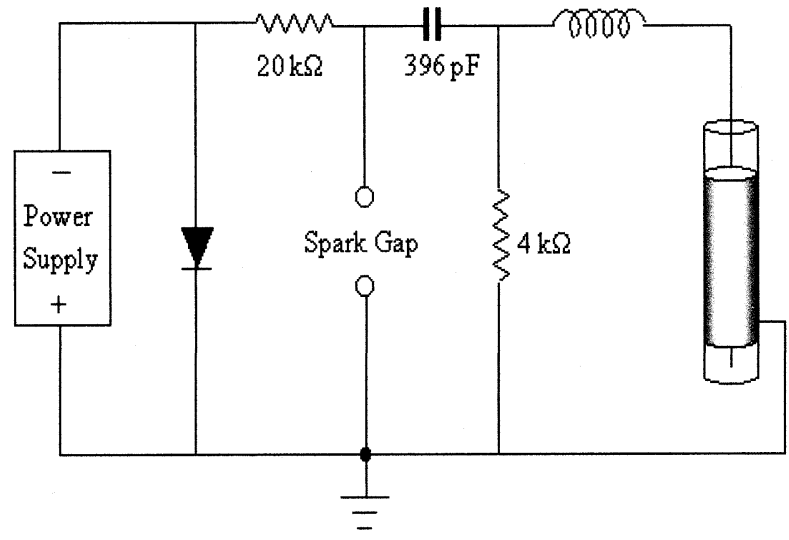

Fig. 2. Schematic of the spark-gap pulse generator.

\section{B. Discharge Power Measurement}

The method adopted to measure the discharge power when the ac voltage was applied to the reactor is as follows [22]-[24]. A 1.0 $\mu \mathrm{F}$ capacitor was connected in series with the reactor as shown in the Fig. 1. Since the dielectric barrier discharge reactor can be considered as a capacitor, the charge stored in the capacitor $(1.0-\mu \mathrm{F})$ is equal to that in the reactor. The charge stored in the capacitor $(Q)$ is the product of capacitance and voltage (CV, C: capacitance; V: voltage), which can be directly read by the voltage between both ends of the capacitor. In other words, the charge stored in the capacitor is equal to $10^{-6}$ times the voltage. Fig. 3(a) shows an example of the voltage waveforms measured at the discharging electrode and at the $1.0 \mu \mathrm{F}$ capacitor, and Fig. 3(b) shows the charge-voltage plot at the corresponding voltage. The area of the parallelogram in Fig. 3(b) conforms to the discharge energy per one cycle, and the average discharge power can be obtained by multiplying the discharge energy per one cycle by ac frequency (i.e., $60 \mathrm{~Hz}$ ). For example, in Fig. 3(b), the discharge energy per cycle at $12 \mathrm{kV}$ was found to be $7.33 \mathrm{~mJ} /$ cycle. Hence, the average discharge power is $7.33 \times 10^{-3} \mathrm{~J} /$ cycle $\times 60 \mathrm{~Hz}=0.44 \mathrm{~W}$. A mathematical formula is available for calculating the area of the parallelogram [22]-[24]. For convenience, in the present case, the area of parallelogram was calculated by comparing the total mass of the graph with that of the parallelogram. It was assumed that the thickness of the paper was uniform throughout. We com-

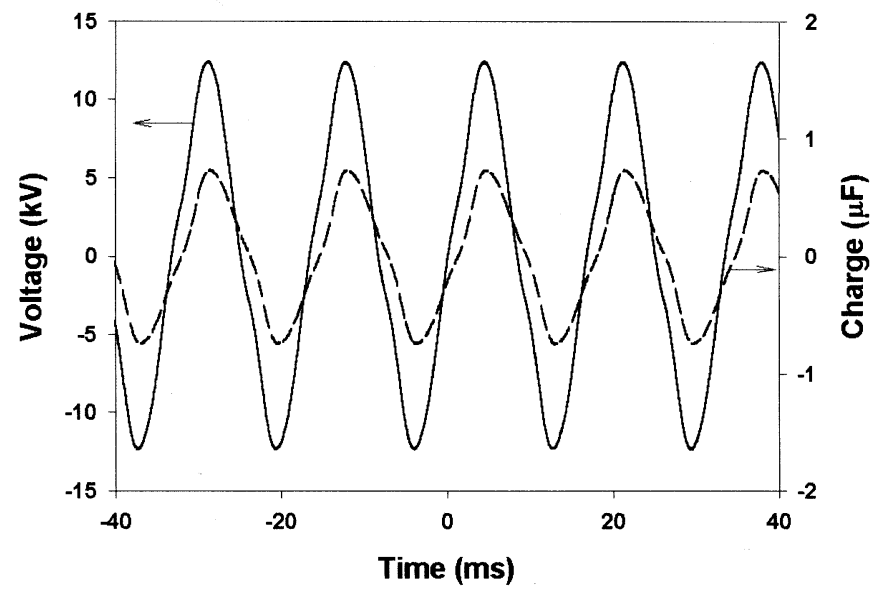

(a)

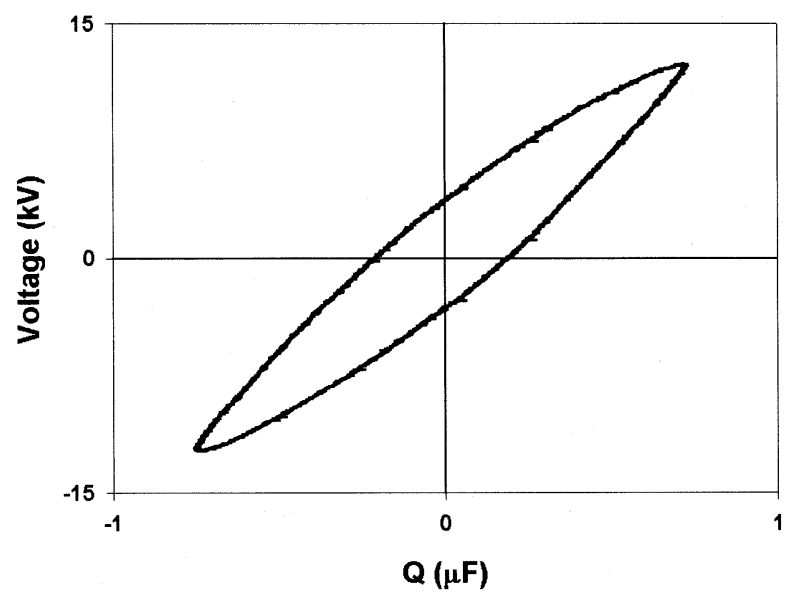

(b)

Fig. 3. (a) Voltage waveforms measured at the discharging electrode and at the $1.0 \mu \mathrm{F}$ capacitor. (b) Corresponding charge-voltage plot (oxygen content: $10 \%$ $(\mathrm{v} / \mathrm{v})$; temperature: $\left.100{ }^{\circ} \mathrm{C}\right)$.

pared both methods of calculating the area of the parallelogram and the results were found to agree well within 5\%.

When pulse voltage was applied, the average discharge power was obtained with the voltage and current forms. Fig. 4 shows the pulse voltage and current waveforms measured at the discharging electrode and the grounded aluminum foil, 


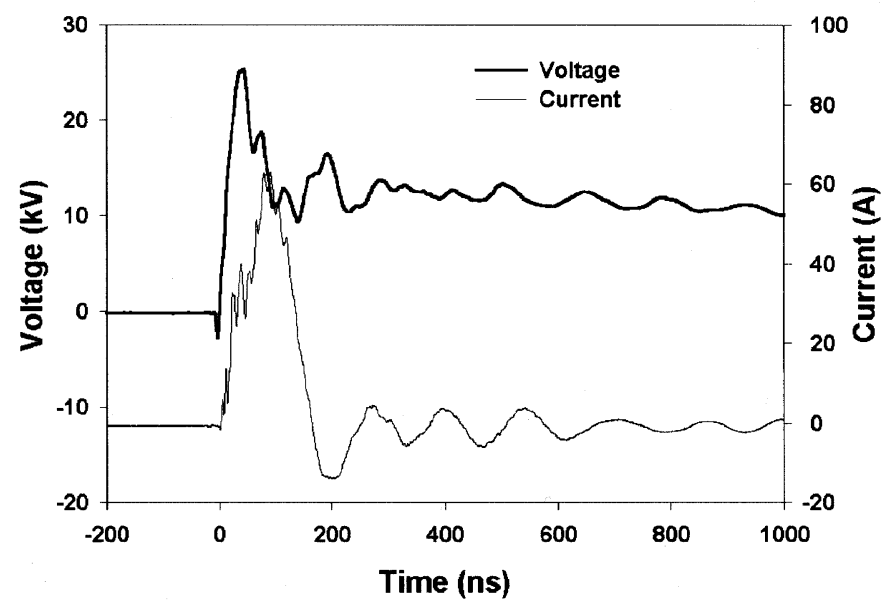

Fig. 4. Pulse voltage and current waveforms (charging voltage: $23 \mathrm{kV}$; oxygen content: $10 \%(\mathrm{v} / \mathrm{v})$; temperature: $\left.100{ }^{\circ} \mathrm{C}\right)$.

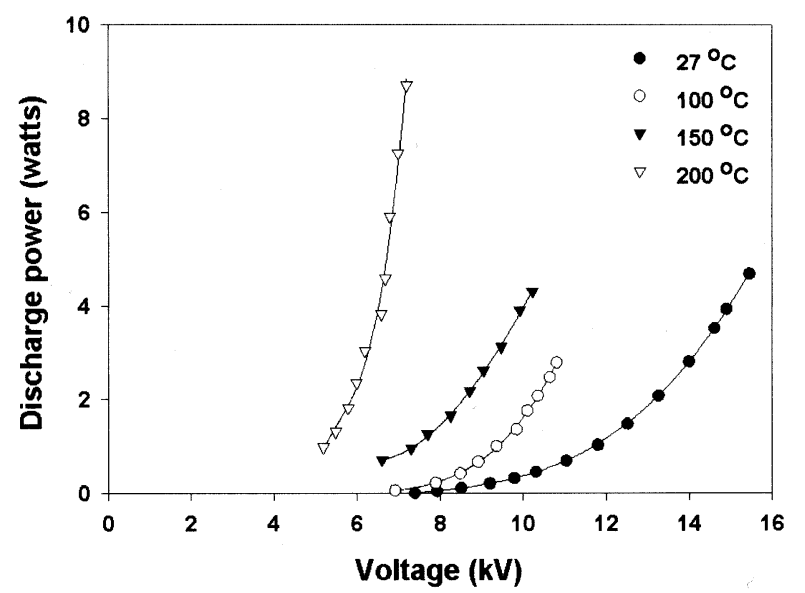

Fig. 5. Discharge power as a function of applied voltage at different temperatures [oxygen content: $10 \%(\mathrm{v} / \mathrm{v})$ ].

respectively. The rise time of the pulse voltage (10\%-90\%) was $11 \mathrm{~ns}$, and the pulsewidth (full width at half maximum) was about $200 \mathrm{~ns}$. The integration of the product of these voltage and current waveforms corresponds to the discharge energy per pulse. In this case, the discharge energy per pulse was calculated to be $86.7 \mathrm{~mJ} /$ pulse. The average discharge power was obtained by multiplying the discharge energy per pulse by the pulse repetition rate.

\section{RESULTS AND DISCUSSION}

\section{A. Plasma Reactor}

Fig. 5 shows the discharge power curves as a function of applied voltage at different temperatures. The occurrence of discharge ignition shifted toward lower voltages and the discharge power largely increased with the increase in temperature. The discharge ignition voltage that gives nonzero discharge power was calculated by extrapolating each curve. At $27^{\circ} \mathrm{C}, 100{ }^{\circ} \mathrm{C}$, $150{ }^{\circ} \mathrm{C}$, and $200^{\circ} \mathrm{C}$, the respective discharge ignition voltages were found to be 7.4, 6.7, 5.5, and $4 \mathrm{kV}$. This lower discharge ignition voltage and higher discharge power at higher temperature can be explained as follows. When pressure is constant, the gas density $(n)$ decreases with the increase in temperature, which

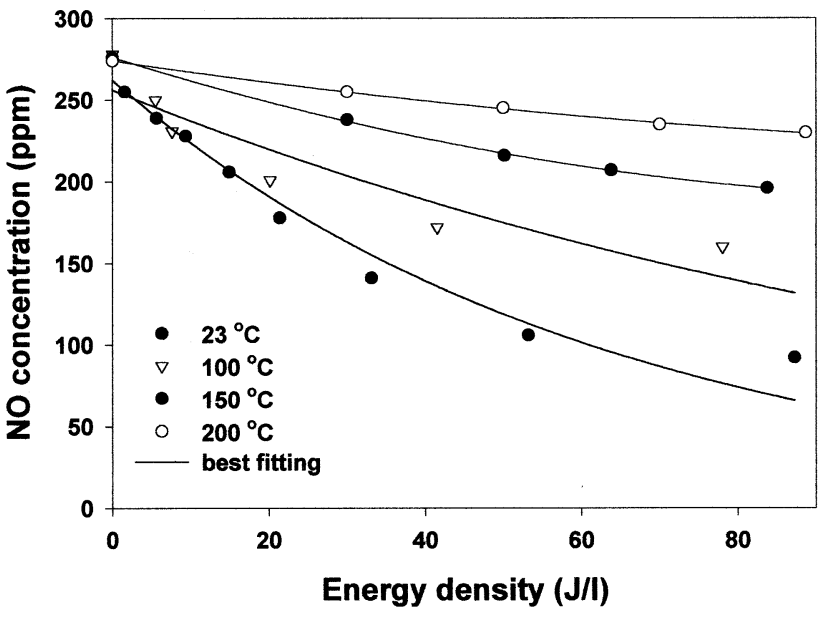

Fig. 6. NO concentration profiles using plasma reactor in the absence of ethylene [oxygen content: $10 \%(\mathrm{v} / \mathrm{v})]$.

leads to the increase in the reduced electric field $(E / n)$ [25]. Since the dielectric breakdown of the gas discharge occurs at a certain reduced electric field, the increase in temperature results in the decrease in discharge ignition voltage. Therefore, the gas at high temperature can be more easily ionized. As the extent of ionization increases, the discharge current increases because of decreased gas resistance, and the discharge powers increases. The discharge power data in Fig. 5 were used for the calculation of energy density that is defined as the ratio of discharge power to gas flow rate.

Fig. 6 shows the concentration profiles of $\mathrm{NO}$ as a function of energy density at different temperatures. In a gas mixture of the present case, the $\mathrm{NO}$ removal takes place mainly by its oxidation to $\mathrm{NO}_{2}$ [7], [8], [26]. At room temperature, $\mathrm{NO}$ was easily depleted. As the temperature increased, however, the rate of $\mathrm{NO}$ conversion largely decreased. The decrease in NO conversion with temperature can be explained with the rates of the relevant reactions. Main reactions for this case of $\mathrm{NO}$ oxidation are as follows [27], [28]:

$$
\begin{aligned}
& \mathrm{NO}+\mathrm{O} \rightarrow \mathrm{NO}_{2} \quad k_{1}=5.0 \times 10^{-33} \exp (900 / \mathrm{T})[\mathrm{M}] \\
& \mathrm{NO}+\mathrm{O}_{3} \rightarrow \mathrm{NO}_{2}+\mathrm{O}_{2} \\
& k_{2}=1.0 \times 10^{-31}(300 / \mathrm{T}) 1.6[\mathrm{M}] \\
& \mathrm{O}+\mathrm{O}_{2} \rightarrow \mathrm{O}_{3} \quad k_{3}=5.6 \times 10^{-34}(300 / \mathrm{T}) 2.23[\mathrm{M}] \\
& \mathrm{O}+\mathrm{O}_{3} \rightarrow 2 \mathrm{O}_{2} \quad k_{4}=8.0 \times 10^{-12} \exp (-2060 / \mathrm{T})
\end{aligned}
$$

According to the previous results, ozone was proved to play an important role in the oxidation of $\mathrm{NO}$ at room temperature [26]. As can be understood in (3) and (4), however, generation of ozone decreases much with the increase in temperature and, moreover, the decomposition into molecular oxygen becomes significant as the temperature increases. As a result, (2) cannot contribute to the oxidation of $\mathrm{NO}$ at high temperatures, which can explain why the oxidation rate is lowered. At relatively high temperatures in the range of $100^{\circ} \mathrm{C}-200^{\circ} \mathrm{C}$, the key reaction for the oxidation of $\mathrm{NO}$ is, thus, (1). Since this reaction is in inverse proportion to the temperature, higher temperature gives rise to lower oxidation efficiency of NO. Moreover, the lower oxidation efficiency of $\mathrm{NO}$ at higher temperature can 
also be attributed to the back reaction of $\mathrm{NO}_{2}$ to $\mathrm{NO}$ by $\mathrm{O}$ radical $\left(\mathrm{NO}_{2}+\mathrm{O} \rightarrow \mathrm{NO}+\mathrm{O}_{2}\right)$ [29]. Meanwhile, the $\mathrm{NO}_{x}$ level $\left(\mathrm{NO}+\mathrm{NO}_{2}\right)$ was kept almost constant regardless of the oxidation of $\mathrm{NO}$ although the data were not presented in Fig. 6, which means that $\mathrm{NO}$ was simply converted to $\mathrm{NO}_{2}$.

Since the oxidation of $\mathrm{NO}$ was very slow at high temperatures as previously examined, it was necessary to use a hydrocarbon additive. In this study, the hydrocarbon additive was ethylene. The hydrocarbon plays an important role in enhancing the oxidation of NO [7], [9], [18]. In real flue gases such as diesel exhaust and iron-ore sintering flue gas, some amount of hydrocarbon exists, and they may have similar effect to ethylene on NO conversion. Under plasma discharge, ethylene is decomposed into several fragments such as $\mathrm{CH}_{3}$ and $\mathrm{CH}_{3} \mathrm{O}$ radicals [9], [26], and these radicals can enhance the oxidation of $\mathrm{NO}$ via several reactions. Methyl radical $\left(\mathrm{CH}_{3}\right)$ can react with oxygen which is one of the major constituents of the feed gas as follows [27]:

$\mathrm{CH}_{3}+\mathrm{O}_{2} \rightarrow \mathrm{CH}_{3} \mathrm{O}_{2} \quad k_{5}=7.56 \times 10^{-31}(\mathrm{~T} / 298)-3.64[\mathrm{M}]$

This intermediate $\mathrm{CH}_{3} \mathrm{O}_{2}$ converts $\mathrm{NO}$ to $\mathrm{NO}_{2}$ by changing its oxidation state as below [27]

$$
\begin{aligned}
\mathrm{NO}+\mathrm{CH}_{3} \mathrm{O}_{2} \rightarrow \mathrm{NO}_{2}+\mathrm{CH}_{3} \mathrm{O} & \\
& k_{6}=2.8 \times 10^{-12} \exp (285 / \mathrm{T}) .
\end{aligned}
$$

Methoxy radical $\left(\mathrm{CH}_{3} \mathrm{O}\right)$ formed in (6) reacts with oxygen to generate formaldehyde $(\mathrm{HCHO})$ and $\mathrm{HO}_{2}$ radical. $\mathrm{HO}_{2}$ is a strong oxidizing radical capable of oxidizing $\mathrm{NO}$ to $\mathrm{NO}_{2}$ [27]

$$
\begin{aligned}
& \mathrm{CH}_{3} \mathrm{O}+\mathrm{O}_{2} \rightarrow \mathrm{HCHO}+\mathrm{HO}_{2} \\
& k_{7}=7.2 \times 10^{-14} \exp (-1080 / \mathrm{T}) \\
& \mathrm{NO}+\mathrm{HO}_{2} \rightarrow \mathrm{NO}_{2}+\mathrm{OH} \\
& k_{8}=3.4 \times 10^{-12} \exp (270 / \mathrm{T}) .
\end{aligned}
$$

Formaldehyde reacts with $\mathrm{OH}$ radical to form $\mathrm{HCO}$, which, in turn, gives rise to carbon monoxide and carbon dioxide as [27], [28]

$$
\begin{aligned}
& \mathrm{HCHO}+\mathrm{OH} \rightarrow \mathrm{HCO}+\mathrm{H}_{2} \mathrm{O} \\
& k_{9}=1.66 \times 10^{-11} \exp (-86 / \mathrm{T}) \\
& \mathrm{HCO}+\mathrm{O}_{2} \rightarrow \mathrm{CO}+\mathrm{HO}_{2} \\
& k_{10}=3.5 \times 10^{-12} \exp (140 / \mathrm{T}) \\
& \mathrm{HCO}+\mathrm{O} \rightarrow \mathrm{CO}+\mathrm{OH} \quad k_{11}=5 \times 10^{-11} \\
& \mathrm{HCO}+\mathrm{O} \rightarrow \mathrm{H}+\mathrm{CO}_{2} \quad k_{12}=5 \times 10^{-11} .
\end{aligned}
$$

The other important scheme leading to the oxidation of $\mathrm{NO}$ to $\mathrm{NO}_{2}$ are as follows [9]:

$$
\begin{aligned}
& \mathrm{C}_{2} \mathrm{H}_{4}+\mathrm{OH} \rightarrow \mathrm{C}_{2} \mathrm{H}_{4} \mathrm{OH} \\
& \mathrm{C}_{2} \mathrm{H}_{4} \mathrm{OH}+2 \mathrm{O}_{2}+2 \mathrm{NO} \rightarrow 2 \mathrm{HCHO}+2 \mathrm{NO}_{2}+2 \mathrm{OH} .
\end{aligned}
$$

Since these reactions are initiated by $\mathrm{OH}$ radical, they are more pronounced when water vapor is present in the feed gas stream.

As explained in (5)-(14), the addition of ethylene can promote the oxidation of $\mathrm{NO}$, and the results obtained in the pres-

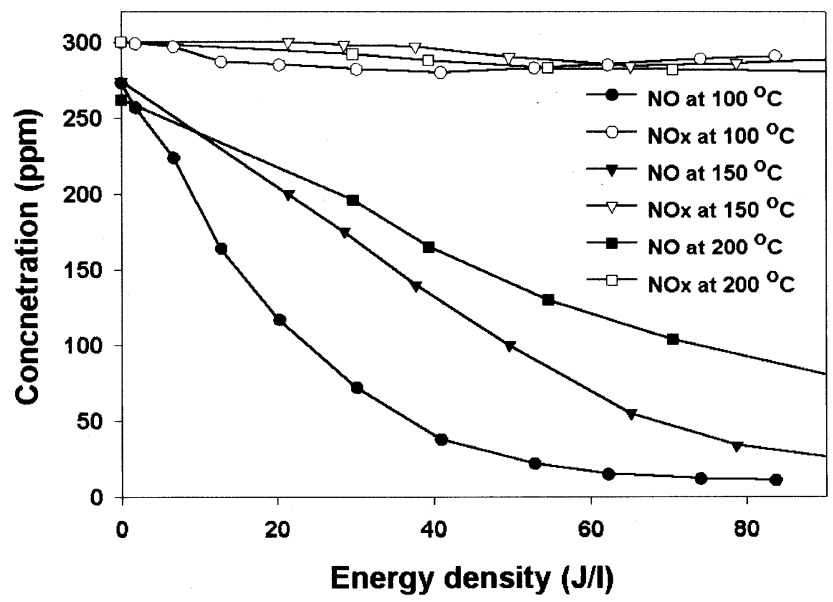

Fig. 7. $\mathrm{NO}$ and $\mathrm{NO}_{x}$ concentration profiles using plasma reactor in presence of ethylene (oxygen content: $10 \%(\mathrm{v} / \mathrm{v}) ; \mathrm{C}_{2} \mathrm{H}_{4}: 750 \mathrm{ppm}$ ).

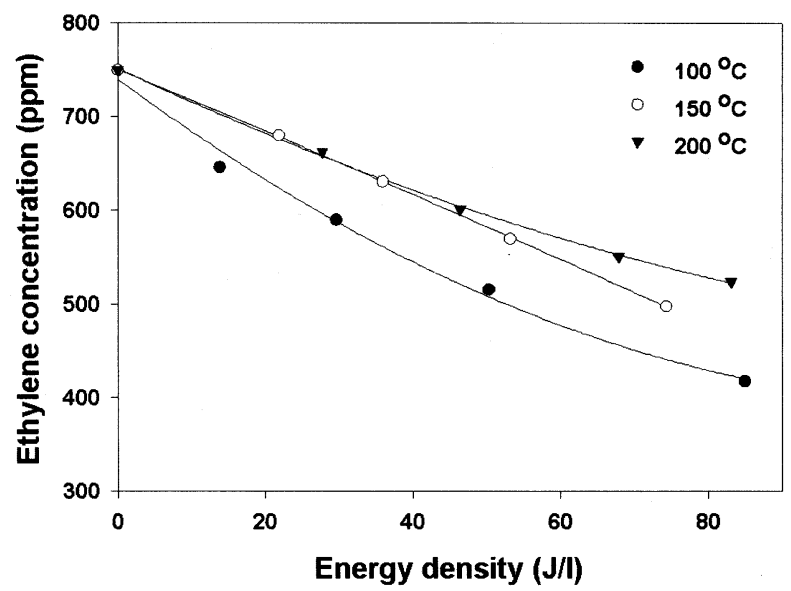

Fig. 8. Concentration of ethylene at the outlet of the plasma reactor as a function of energy density (oxygen content: $10 \%(\mathrm{v} / \mathrm{v}) ; \mathrm{C}_{2} \mathrm{H}_{4}: 750 \mathrm{ppm}$ ).

ence of ethylene are shown in Fig. 7. The presence of ethylene dramatically increased the NO oxidation. Despite the addition of ethylene, however, no reduction in $\mathrm{NO}_{x}$ level was observed just as the case in the absence of it. In Fig. 7, the difference between $\mathrm{NO}_{x}$ and $\mathrm{NO}$ concentrations corresponds to $\mathrm{NO}_{2}$ concentration. As mentioned, the changes in the ratio of $\mathrm{NO}_{2}$ to $\mathrm{NO}$ may affect the performance of SCR catalyst. In this sense, it can be said that the increase in $\mathrm{NO}_{2}$ portion by the oxidation of $\mathrm{NO}$ is important when nonthermal plasma is combined with SCR catalyst. In the meantime, the increase in temperature decreased the oxidation of NO, and accordingly, more energy was required to convert the identical amount of $\mathrm{NO}$ at higher temperature. For example, the energy density required to obtain equimolar composition of $\mathrm{NO}$ and $\mathrm{NO}_{2}$, i.e., to make both $\mathrm{NO}$ and $\mathrm{NO}_{2} 150 \mathrm{ppm}$, were 15,35 , and $45 \mathrm{~J} / 1$ at $100{ }^{\circ} \mathrm{C}, 150{ }^{\circ} \mathrm{C}$, and $200^{\circ} \mathrm{C}$, respectively. In the present study, the effect of water vapor on the conversion of NO was not investigated, but in the presence of water vapor much smaller influence of the temperature on the conversion of NO was reported [30].

Fig. 8 shows the concentrations of unreacted ethylene emitted from the plasma reactor. As observed, the concentration of ethylene was higher at higher reaction temperature. According to 


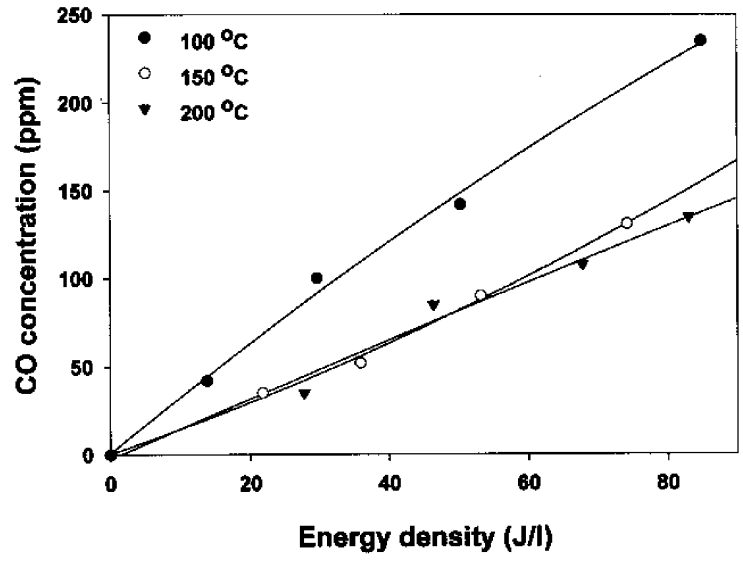

Fig. 9. Concentration of $\mathrm{CO}$ at the outlet of the plasma reactor as a function of energy density (oxygen content: $\left.10 \%(\mathrm{v} / \mathrm{v}) ; \mathrm{C}_{2} \mathrm{H}_{4}: 750 \mathrm{ppm}\right)$.

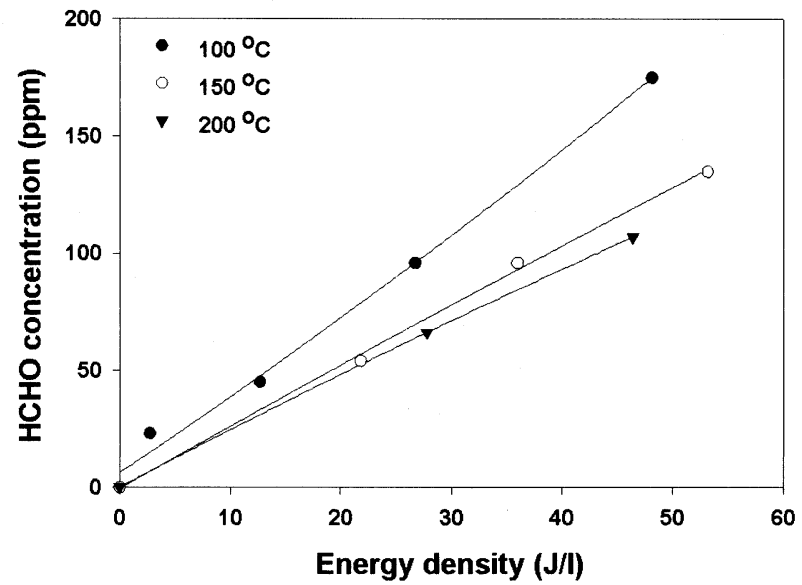

Fig. 10. Concentration of $\mathrm{HCHO}$ at the outlet of the plasma reactor as a function of energy (oxygen content: $\left.10 \%(\mathrm{v} / \mathrm{v}) ; \mathrm{C}_{2} \mathrm{H}_{4}: 750 \mathrm{ppm}\right)$.

the previous results, the decomposition of ethylene is mainly caused by the active species such as $\mathrm{O}, \mathrm{OH}$, and $\mathrm{O}_{3}$. However, since this temperature range is too high to form ozone and in addition there is no water vapor, the reaction of ethylene with $\mathrm{O}$ radical dominates the decomposition. Since this reaction decreases with temperature [27], higher concentration of ethylene was observed at higher temperature. From (7) to (14), it can be seen that ethylene, while taking part in $\mathrm{NO}$ oxidation reactions, gives rise to some byproducts such as $\mathrm{CO}, \mathrm{CO}_{2}$, and $\mathrm{HCHO}$. Among these byproducts, $\mathrm{CO}$ and $\mathrm{HCHO}$ are known as harmful pollutants. The formation of any other byproduct was confirmed to be negligible after analyzing the treated gas by gas chromatograph. Figs. 9 and 10 show the formation of carbon monoxide and formaldehyde. The formation of these byproducts decreases with the temperature, which is in accordance with the results of ethylene decomposition (see Fig. 8).

In general, DBD reactors are energized by ac voltage, however, some researchers have employed pulse energized DBD reactors [20]-[22]. In order to compare the performances of ac and pulse voltages in terms of $\mathrm{NO}$ conversion, experiments were carried out using both voltage sources. Fig. 11 compares ac with pulse voltage in terms of NO conversion efficiency as a

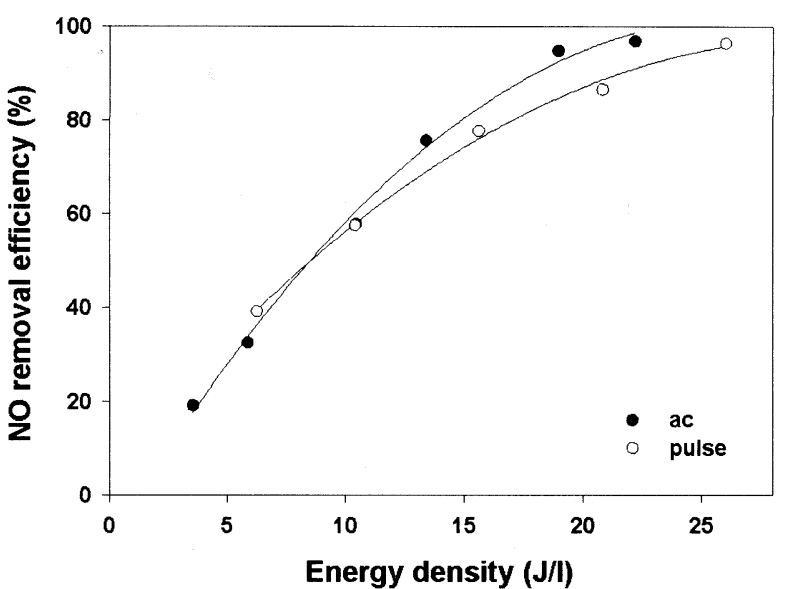

Fig. 11. Comparison of ac with pulse voltage in terms of NO conversion (oxygen content: $10 \%$ (v/v); $\mathrm{C}_{2} \mathrm{H}_{4}$ addition: $750 \mathrm{ppm}$; temperature: $100^{\circ} \mathrm{C}$ ).

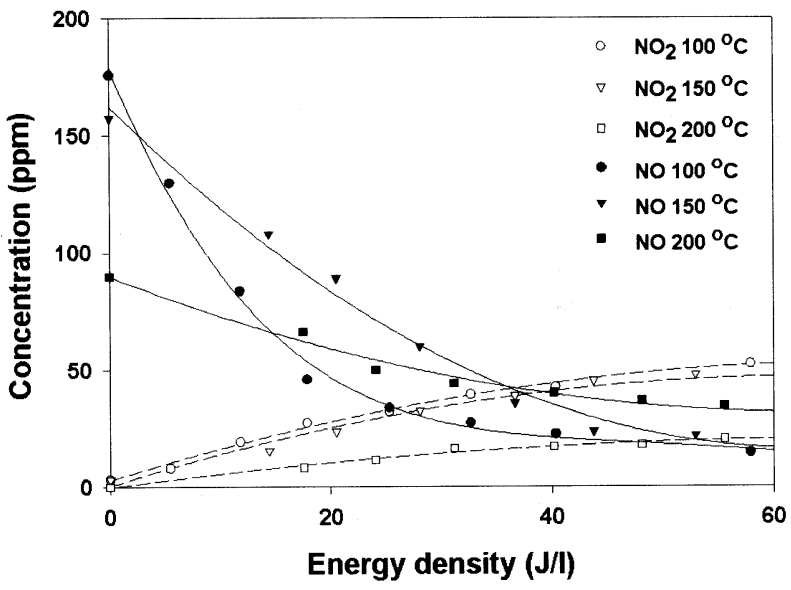

Fig. 12. Effect of energy density on $\mathrm{NO}$ and $\mathrm{NO}_{2}$ concentrations in the plasma-catalytic system (oxygen content: $10 \%(\mathrm{v} / \mathrm{v}) ; \mathrm{C}_{2} \mathrm{H}_{4}$ addition: $750 \mathrm{ppm}$; $\mathrm{NH}_{3}: 300 \mathrm{ppm}$ ).

function of energy density. It was found that the NO conversion efficiencies were almost equal regardless of the type of the voltage applied. Since both voltages perform equally, choice can be made depending on cost, reliability, and compatibility. In the present study, further experiments were conducted using ac voltage only.

\section{B. Plasma Catalytic Reactor}

Fig. 12 shows the concentration profiles of $\mathrm{NO}$ and $\mathrm{NO}_{2}$ at the outlet of the plasma-catalytic reactor when $300 \mathrm{ppm}$ of ammonia was added. The experimental reproducibility for the plasma reactor was very good. When the catalyst was combined with plasma reactor, however, each experiment conducted at identical condition gave a slightly different result in the $\mathrm{NO}$ and $\mathrm{NO}_{2}$ concentration. The maximum concentration discrepancy was $10 \mathrm{ppm}$, corresponding to about $3 \%$ removal efficiency (initial $\mathrm{NO}_{x}$ concentration: $300 \mathrm{ppm}$ ). Although the data in Fig. 12 are the average values of the data repeated several times, they may include some experimental errors. Referring to the literature [6], [11], the gas mixture should contain $\mathrm{NO}_{2}$ for efficient catalytic removal of $\mathrm{NO}_{x}$ because the adsorption capability of 
$\mathrm{NO}_{2}$ is larger than that of $\mathrm{NO}$. When ammonia is added as a reducing agent, $\mathrm{NO}_{2}$ not only reacts with the gas phase $\mathrm{NO}$ fast, but is also easily decomposed into nitrogen as follows [10], [31]:

$$
\begin{aligned}
& \mathrm{NO}+\mathrm{NO}_{2}+2 \mathrm{NH}_{3} \rightarrow 2 \mathrm{~N}_{2}+3 \mathrm{H}_{2} \mathrm{O} \\
& 6 \mathrm{NO}_{2}+8 \mathrm{NH}_{3} \rightarrow 7 \mathrm{~N}_{2}+12 \mathrm{H}_{2} \mathrm{O} .
\end{aligned}
$$

Equation (15) implies that the concentrations of $\mathrm{NO}$ and $\mathrm{NO}_{2}$ should be equal, and (16) signifies the importance of $\mathrm{NO}_{2}$, which reaches a conclusion that at least the concentration of $\mathrm{NO}_{2}$ should be the same with that of NO. The results in Fig. 12 clearly show the significance of the plasma discharge in the removal of $\mathrm{NO}_{x}$ on catalyst. For example, in the absence of plasma discharge, the catalyst removed $40 \%, 46 \%$, and $70 \%$ of $\mathrm{NO}_{x}$ at $100{ }^{\circ} \mathrm{C}, 150{ }^{\circ} \mathrm{C}$, and $200{ }^{\circ} \mathrm{C}$, respectively. In the presence of plasma discharge, $\mathrm{NO}_{x}$ removal was nearly $80 \%$ at all temperatures at an energy density of $40 \mathrm{~J} / \mathrm{l}$. Since the plasma reactor alone hardly gave any reduction in $\mathrm{NO}_{x}$ level as shown in Fig. 7, it can be said that the enhancement in the $\mathrm{NO}_{x}$ removal efficiency in the presence of plasma discharge resulted from the increase in $\mathrm{NO}_{2}$ concentration. Such synergistic effect was more significant as the temperature decreased, which indicates that the performance of SCR can largely be enhanced especially at low temperatures. The removal efficiency of $80 \%$ is tantamount to an energy yield of $42-\mathrm{eV} / \mathrm{NO}_{x}$ molecule. Miessner et al. [31] reported that with an energy input of about $30 \mathrm{eV} / \mathrm{NO}_{x}$-molecule, $500 \mathrm{ppm} \mathrm{NO}$ was reduced by more than half at a temperature of $300{ }^{\circ} \mathrm{C}$. Bröer and Hammer [10] showed that with an energy input of $20-\mathrm{eV} / \mathrm{NO}_{x}$ molecule a $\mathrm{NO}_{x}$ reduction of more than $85 \%$ was achieved at temperatures above $160{ }^{\circ} \mathrm{C}$, and at $130{ }^{\circ} \mathrm{C}$ about $50 \%$ reduction. This value of $20-\mathrm{eV} / \mathrm{NO}_{x}$ molecule is higher than that obtained here, but the energy yields cannot directly be compared because the catalyst, the initial concentration of $\mathrm{NO}_{x}$ and the operating condition are different one another.

As observed in Figs. 9 and 10, significant amounts of formaldehyde and carbon monoxide as a result of ethylene decomposition were emitted from the plasma reactor. These byproducts were also measured at the outlet of the plasma-catalytic reactor, and the results are shown in Fig. 13. Formaldehyde was found to be completely removed on the catalyst surface, i.e., the concentration was always zero in this experimental condition. Besides, in the gas chromatogram obtained by using the flame ionization detector, no peaks other than ethylene were observed, implying that no organic species were formed from ethylene. On the other hand, the emission of $\mathrm{CO}$ at the outlet of the plasma-catalytic reactor was significant, especially at high temperature. Further studies are thus required to bring down the $\mathrm{CO}$ level to allowable limit for practical application of this system. Otherwise, the use of another additive capable of promoting the oxidation of $\mathrm{NO}$ to $\mathrm{NO}_{2}$ without evolving $\mathrm{CO}$ may be preventive measures against this problem. One candidate of chemical additive for this purpose may be hydrogen peroxide [32].

The emission of unreacted ammonia is called as ammonia slip that should be kept as low as possible. An attempt was made

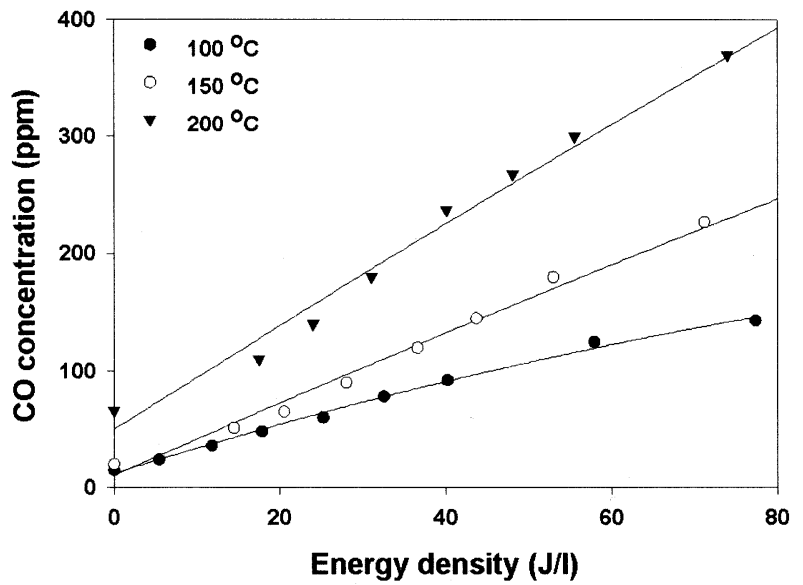

Fig. 13. Effect of energy density on $\mathrm{CO}$ concentration in the plasma-catalytic system (oxygen content: $10 \%$ (v/v); $\mathrm{C}_{2} \mathrm{H}_{4}$ addition: $750 \mathrm{ppm} ; \mathrm{NH}_{3}: 300 \mathrm{ppm}$ )

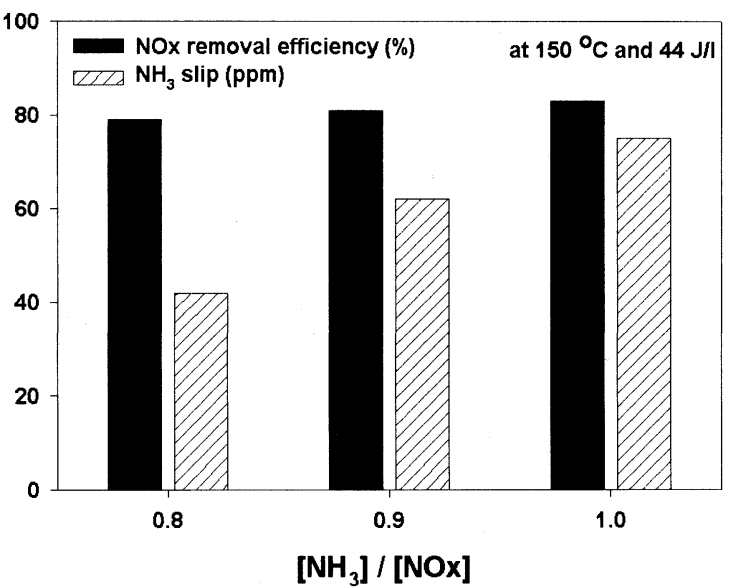

Fig. 14. Removal efficiency of $\mathrm{NO}_{x}$ and ammonia slip as a function of concentration ratio of ammonia to initial $\mathrm{NO}_{x}$ (oxygen content: $10 \%(\mathrm{v} / \mathrm{v})$; $\mathrm{C}_{2} \mathrm{H}_{4}$ addition: $750 \mathrm{ppm}$; temperature: $150{ }^{\circ} \mathrm{C}$ ).

to minimize the $\mathrm{NH}_{3}$ slip by decreasing the ratio $\left[\mathrm{NH}_{3}\right] /\left[\mathrm{NO}_{x}\right]$ from 1.0 to 0.8 (see Fig. 14). As the concentration ratio of ammonia to initial $\mathrm{NO}_{x}$ decreased, the ammonia slip decreased while retaining almost similar $\mathrm{NO}_{x}$ removal efficiency. At a ratio of 0.8 , for example, the $\mathrm{NO}_{x}$ removal was decreased by only $4 \%$ with the corresponding decrease of $30 \mathrm{ppm}$ in $\mathrm{NH}_{3}$. This drop in $\mathrm{NH}_{3}$ slip without compensating much of the $\mathrm{NO}_{x}$ removal efficiency suggests the existence of other removal pathways involving ethylene and formaldehyde present in the gas mixture. According to the literature [12], formaldehyde can take part in the reduction of $\mathrm{NO}_{x}$ on the catalyst. It is believed that similar phenomenon took place in this system, too. If other removal pathways do not exist, negligible $\mathrm{NH}_{3}$ slip should be observed because the amount of $\mathrm{NH}_{3}$ added is nearly equal to that of $\mathrm{NO}_{x}$ removed. The other plausible reason that may account for the ammonia slip is the release of $\mathrm{NH}_{3}$ stored in the catalyst. The stored ammonia may contribute significantly to the ammonia slip and the $\mathrm{NO}_{x}$ reduction. Since the results in Fig. 14 are not the values taken by allowing sufficient time, further experimental verification for an extended time should be performed. 


\section{CONCLUSION}

The following conclusions were drawn from the present studies on the plasma-catalyst combination system.

1) NO conversion efficiencies were found to be almost equal regardless of the applied voltage types such as ac and pulse.

2) For the effective NO oxidation using plasma reactor at high temperature, it is necessary to add an additive such as ethylene to the gas mixture.

3) The important role of plasma reactor in the plasma catalytic reactor is mainly to oxidize $\mathrm{NO}$ to $\mathrm{NO}_{2}$. The selective catalytic reduction of $\mathrm{NO}_{x}$ was largely enhanced when the gas mixture consisted of both $\mathrm{NO}$ and $\mathrm{NO}_{2}$.

4) With catalyst alone, the $\mathrm{NO}_{x}$ reduction was $40 \%, 46 \%$, and $70 \%$ at $100{ }^{\circ} \mathrm{C}, 150{ }^{\circ} \mathrm{C}$, and $200{ }^{\circ} \mathrm{C}$ whereas with plasma-catalytic reactor the $\mathrm{NO}_{x}$ removal efficiency was around $80 \%$ at all temperatures that are much lower than typical reaction temperature of selective catalytic reduction. With the plasma reactor alone, almost no reduction in $\mathrm{NO}_{x}$ level was observed. The differences between the summation of individual $\mathrm{NO}_{x}$ removal efficiencies of plasma and catalytic reactors, and the removal efficiencies of the plasma-catalytic reactor were $40 \%, 34 \%$, and $10 \%$ at $100{ }^{\circ} \mathrm{C}, 150{ }^{\circ} \mathrm{C}$, and $200{ }^{\circ} \mathrm{C}$, respectively. The removal efficiency of $80 \%$ at an energy density of $40 \mathrm{~J} / \mathrm{l}$ corresponds to an energy yield of $42 \mathrm{eV} / \mathrm{NO}_{x}$-molecule.

5) One of the main byproduct, formaldehyde produced in the plasma reactor was decomposed completely in the plasma-catalytic reactor. This may be an indication that the formaldehyde can take part in the $\mathrm{NO}_{x}$ removal. However, significant amount of $\mathrm{CO}$ emission should be properly managed for the practical application of this process.

\section{REFERENCES}

[1] K. Kawamura and V. H. Shui, "Pilot plant experience in electron-beam treatment of iron-ore sintering flue gas and its application to coal boiler flue gas clean-up," Radiat. Phys. Chem., vol. 24, no. 1, pp. 117-127, 1984.

[2] K. Yan, H. Hui, M. Cui, J. Miao, X. Wu, C. Bao, and R. Li, “Corona-induced nonthermal plasmas: Fundamental study and industrial applications," J. Electrostat., vol. 44, pp. 17-39, 1998.

[3] B. Westerberg, C. Kunkel, and C. U. I. Odenbrand, "Optimization of a dosing strategy for an HC-SCR diesel exhaust after-treatment system," Chem. Eng. J., vol. 87, pp. 207-217, 2002.

[4] G. W. Selby and R. M. Counce, "Aqueous scrubbing of dilute nitrogen oxide gas mixtures," Ind. Eng. Chem. Res., vol. 27, pp. 1917-1922, 1988.

[5] M. Koebel and M. Elsener, "Selective catalytic reduction of NO over

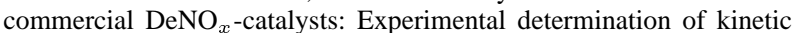
and thermodynamic parameters," Chem. Eng. Sci., vol. 53, no. 4, pp. 657-669, 1998.

[6] F. Luck and J. Roiron, "Selective catalytic reduction of $\mathrm{NO}_{x}$ emitted by nitric acid plants," Catal. Today, vol. 4, pp. 205-218, 1989.

[7] Y. S. Mok, J. H. Kim, S. W. Ham, and I. Nam, "Removal of NO and formation of byproducts in a positive pulsed corona discharge reactor," Ind. Eng. Chem. Res., vol. 39, no. 10, pp. 3938-3944, 2000.

[8] B. M. Penetrante, R. M. Brusasco, B. T. Merritt, and G. E. Vogtlin, "Environmental applications of low-temperature plasmas," Pure Appl. Chem., vol. 71, no. 10, pp. 1829-1835, 1999.

[9] G. Sathiamoorthy, S. Kalyana, W. C. Finney, R. J. Clark, and B. R. Locke, "Chemical reaction kinetics and reactor modeling of $\mathrm{NO}_{x}$ removal in a pulsed streamer corona discharge reactor," Ind. Eng. Chem. Res., vol. 38, no. 5, pp. 1844-1855, 1999.
[10] S. Bröer and T. Hammer, "Selective catalytic reduction of nitrogen oxides by combining a nonthermal plasma and a $\mathrm{V}_{2} \mathrm{O}_{5}-\mathrm{WO}_{3} / \mathrm{TiO}_{2}$ catalyst," Appl. Catal. B, Environ., vol. 28, pp. 101-111, 2000.

[11] J. Hoard, "Plasma-Catalysis for Diesel Exhaust Treatment: Current State of Art," SAE, Paper 01FL-63, 2001.

[12] S. Yoon, A. G. Panov, R. G. Tonkyn, A. C. Ebeling, S. E. Barlow, and M. L. Balmer, "An examination of the role of plasma treatment for lean $\mathrm{NO}_{x}$ reduction over sodium zeolite $\mathrm{Y}$ and gamma alumina part 1. Plasma assisted $\mathrm{NO}_{x}$ reduction over $\mathrm{NaY}$ and $\mathrm{Al}_{2} \mathrm{O}_{3}$," Catal. Today, vol. 72, pp. 243-250, 2002

[13] L. Civitano, "Industrial application of pulsed corona processing to flue gas," in Non-Thermal Plasma Techniques for Pollution Control, ser. NATO ASI Series. Berlin, Germany: Springer-Verlag, 1993, pt. B, vol. 34, pp. 103-130.

[14] G. Dinelli, L. Civitano, and M. Rea, "Industrial experiments on pulse corona simultaneous removal of $\mathrm{NO}_{x}$ and $\mathrm{SO}_{2}$ from flue gas," IEEE Trans. Ind. Applicat., vol. 26, pp. 535-541, May/June 1990.

[15] K. R. Jang, J. G. Shim, T. S. Park, H. M. Eum, C. M. Nam, and Y. W. Han, "Simultaneous removal of $\mathrm{SO}_{2}$ and $\mathrm{NO}_{x}$ using pulsed power reactor of cylindrical type," in Proc. 3rd Int. Symp. Non-Thermal Plasma Technology for Pollution Control, Cheju, Korea, 2001, pp. 181-186.

[16] A. M. Mearns and K. Ofosu-Asiedu, "Kinetics of reaction of low concentration mixtures of oxides of nitrogen, ammonia and water vapor," $J$. Chem. Technol. Biotechnol., vol. 34A, pp. 341-349, 1984.

[17] Y. S. Mok, H. W. Lee, and Y. J. Hyun, "Behavior of ammonium nitrate formation by the reaction between nitrogen dioxide, ammonia and water vapor," Bull. Marine Environ. Res. Inst., vol. 25, pp. 125-137, Dec. 2001.

[18] A. Mizuno, K. Shimizu, A. Chakrabarti, L. Dascalescu, and S. Furutu, "NO $\mathrm{NO}_{x}$ removal process using pulsed discharge plasma," IEEE Trans. Ind. Applicat., vol. 31, pp. 957-964, Sept./Oct. 1995.

[19] J. D. Moon, G. T. Lee, and S. T. Geum, "Discharge and NO removal characteristics of nonthermal plasma reactor with a heated corona wire," J. Electrostat., vol. 50, pp. 1-15, 2000.

[20] Y. Song, D. Shin, W. Shin, K. Kim, Y. Choi, W. Lee, and S. J. Kim, "Characteristics of nonthermal plasma process for air pollution control," Korean Soc. Atmos. Environ., vol. 16, no. 3, pp. 247-256, 2000.

[21] B. S. Rajanikanth and V. Ravi, "Removal of $\mathrm{NO}_{x}$ from diesel engine exhaust using pulsed electric discharge coupled with a catalytic reactor," in Proc. 12th Int. Symp. High Voltage Engineering, Bangalore, Karnatka, India, 2001, pp. 1283-1286.

[22] L. A. Rosocha, G. K. Anderson, L. A. Bechtold, J. J. Coogan, H. G. Heck, K. Kang, W. H. McCulla, R. A. Tennant, and P. J. Wantuck, "Treatment of hazardous organic wastes using silent discharge plasmas," in Non-Thermal Plasma Techniques for Pollution Control, ser. NATO ASI Series. Berlin, Germany: Springer-Verlag, 1993, pt. B, vol. 34, pp. 281-308.

[23] T. C. Manley, "The electrical characteristics of the ozone discharge," Trans. Electrochem. Soc., vol. 84, pp. 83-96, 1943.

[24] U. Kogelschatz, "Advanced ozone generation," in Process Technologies for Water Treatment, S. Stucki, Ed. New York: Plenum, 1988, pp. 87-120.

[25] J. M. Meeks and J. D. Craggs, Electrical Breakdown of Gases. New York: Wiley, 1978.

[26] Y. S. Mok and I. Nam, "Removal of nitric oxide in apulsed corona discharge reactor," Chem. Eng. Technol, vol. 22, no. 6, pp. 527-532, June 1999.

[27] R. Atkinson, D. L. Baulch, R. A. Cox, R. F. Hampson Jr, J. A. Kerr, and J. Troe, "Evaluated kinetic and photochemical data for atmospheric chemistry," J. Phys. Chem. Ref. Data, vol. 21, no. 6, pp. 1125-1568, 1992.

[28] H. Mäzing, "Chemical kinetics of flue gas cleaning by irradiation with electrons," in Advances in Chemical Physics. New York: Wiley, 1991, vol. LXXX, pp. 315-402.

[29] T. Hammer, T. Kishimoto, H. Miessner, and R. Rudolph, "Plasma Enhanced Selective Catalytic Reduction: Kinetics of $\mathrm{NO}_{x}$-Removal and Byproduct Formation," SAE, Paper 1999-01-3632, 1999.

[30] S. Bröer, T. Hammer, and T. Kishimoto, "NO-removal in hydrocarbon containing gas mixtures induced by dielectric barrier discharges," in Proc. 12th Int. Conf. Gas Discharges and Their Applications, Greifswald, Germany, 1997, pp. 188-191.

[31] H. Miessner, K.-P. Francke, R. Rudolph, and T. Hammer, "NO${ }_{x}$ removal in excess oxygen by plasma-enhanced selective catalytic reduction," Catal. Today, vol. 75, pp. 325-330, 2002.

[32] H. H. Kim, K. Tsunoda, S. Katsura, and A. Mizuno, "A novel plasma reactor for $\mathrm{NO}_{x}$ control using photocatalyst and hydrogen peroxide injection," IEEE Trans. Ind. Applicat., vol. 35, pp. 1306-1310, Nov./Dec. 1999 


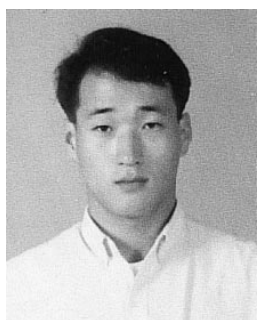

Young Sun Mok was born in Kyungki, Korea, on November 7, 1966. He graduated from Yonsei University, Seoul, Korea in 1989, and received the M.S. and Ph.D. degrees from Korea Advanced Institute of Science and Technology (KAIST), Daejon, Korea, in 1991 and 1994, respectively.

From 1995 to 1996, he was with Pohang Iron and Steel Co., Ltd., Korea, where he was engaged in research on flue gas treatment by nonthermal plasma. In 1996, he joined Research Institute of Industrial Science and Technology, Korea, where he has been in charge of the development of pulsed corona discharge process for removal of $\mathrm{SO}_{x}$ and $\mathrm{NO}_{x}$. Since 2000, he has been with the Department of Chemical Engineering, Cheju National University, Cheju, Korea. His current interests include electrical discharge plasma, microwave discharge, and the combination of plasma technology with catalyst.

Dr. Mok is a Life Member of Korean Institute of Chemical Engineers and a Member of the Korean Society of Environmental Engineers.

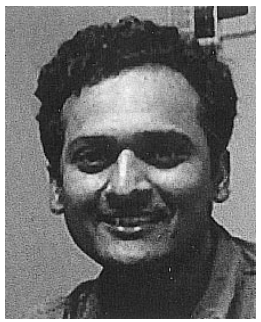

V. Ravi received the M.S. degree in physics from Mangalore University, Karnataka, India, in 1998 an the M.S. degree in engineering from the Department of High Voltage Engineering, Indian Institute of Science (IISc), Bangalore, India, in 2001. He is currently working toward the Ph.D. degree at the IISc.

From July 1998 to December 1999, he was a Research Assistant in the area of glass-ceramics with the Materials Research Center, IISc. He is currently working in the area of applications of electrical discharges for diesel exhaust treatment.

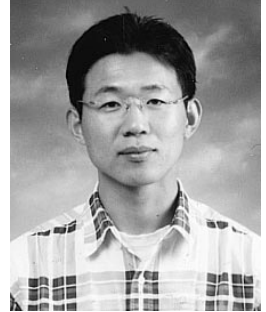

Ho-Chul Kang was born in Jeju Province, Korea, in November, 1976. He graduated from the Department of Chemical Engineering, Cheju National University, Cheju, Korea, in 2002. He is currently working toward the M.S. degree at the same university.

His research interests include the removal of nitrogen oxides and volatile organic compounds by nonthermal plasma combined with catalyst.

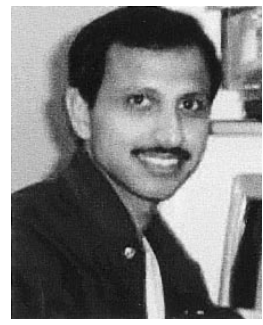

B. S. Rajanikanth (S'93-M'95-SM'00) received the B.E. degree in electrical engineering from Bangalore University, Bangalore, India, in 1987 and the M.S. and Ph.D. degrees in high-voltage engineering from the Indian Institute of Science (IISc), Bangalore, in 1990 and 1993, respectively.

He was a Postdoctoral Research Fellow at Toyohashi University of Technology, Japan, from 1994 to 1996 . He is the Head of the R\&D division at Kirloskar Systems Limited, Bangalore, from 1996 to 1997. He was a Visiting Researcher at Tokyo Metropolitan University during the winter of 1996, and a Visiting Professor at Osaka Metropolitan University during the summer of 2001. He is currently an Assistant Professor in the High Voltage Engineering Department, IISc. His research interests include the applications of high voltages for air pollution control, modeling of electrical characteristics of electrostatic precipitators, optical measurements of high voltages, etc. 